\title{
Pre-hospital system delay and its effect on in-hospital mortality of STEMI patients
}

Magdalena Żurowska-Wolak EMT-P, PhD ${ }^{1,2}$, Jacek Jakała MD, PhD ${ }^{3}$ 1 Division of Emergency Medical Services, Faculty of Health Sciences, Jagiellonian University Medical College, Kraków, Poland 2 Kraków Ambulance Service, Kraków, Poland 3 Department of Cardiology, St. Raphael's Hospital, Kraków, Poland

\section{BACKGROUND}

Acute coronary syndromes (ACS) are a major health problem in Poland and all over the world. Mortality in myocardial infarction depends on several factors, including the time and the type of treatment used. High density of intervention centers in Poland allows the use of reperfusion therapy such as percutaneous coronary intervention (PCI). Diagnosis of myocardial infarction is possible dute to pre-hospital ECG and ECG teletransmission and it allows direct referral to the invasive cardiology center. Initial therapy including anti-platelet and anticoagulant medicines, which can be administrated in Polish ambulances enables rapid treatment efficacy.

AIM

The purpose of this study was to investigate the effect of pre-hospital system delays of emergency medical services (EMS) on in-hospital mortality in ST-segment elevation myocardial infarction (STEMI) patients.

\section{MATERIALS AND METHODS}

The pre-hospital and hospital medical records of STEMI patients who used EMS transportation and were treated with primary percutaneous coronary intervention (pPCI) within 60 minutes after admission to the Department of Cardiology, St. Raphael's Hospital, Krakow, Poland, between January 2011 and December 2015 (excluding 2013) were retrospectively reviewed.

\section{RESULTS}

Among 515 respondents meeting this criteria $26(5.0 \%)$ died in the hospital. In the one-dimensional model the duration of prehospital procedures was significantly related to death. Extending this time by 1 minute increased the chances death by $2 \%$ (95\% CI: 1,002-1,04). Multidimensional regression models were performed for all pre-hospital procedures tested. The presented results include the administration of antiplatelet/anticoagulant drugs (heparin, clopidogrel or both) because they were significantly associated with increased death chance in earlier multivariable models. After taking into account the influence of age, sex, presence of diabetes, hypertension, hypercholesterolemia, renal failure, shock and the administration of drugs (heparin, clopidogrel) in the model, the time from first medical contact (FMC) to patient hospital admission was not significantly related to in-hospital death (Table 3 ).

\section{CONCLUSIONS}

Prolonged pre-hospital management is not significantly associated with in-hospital mortality rate
FIGURE 1: Distribution of total ischaemic time (me, IQR)

Healthcare system delay

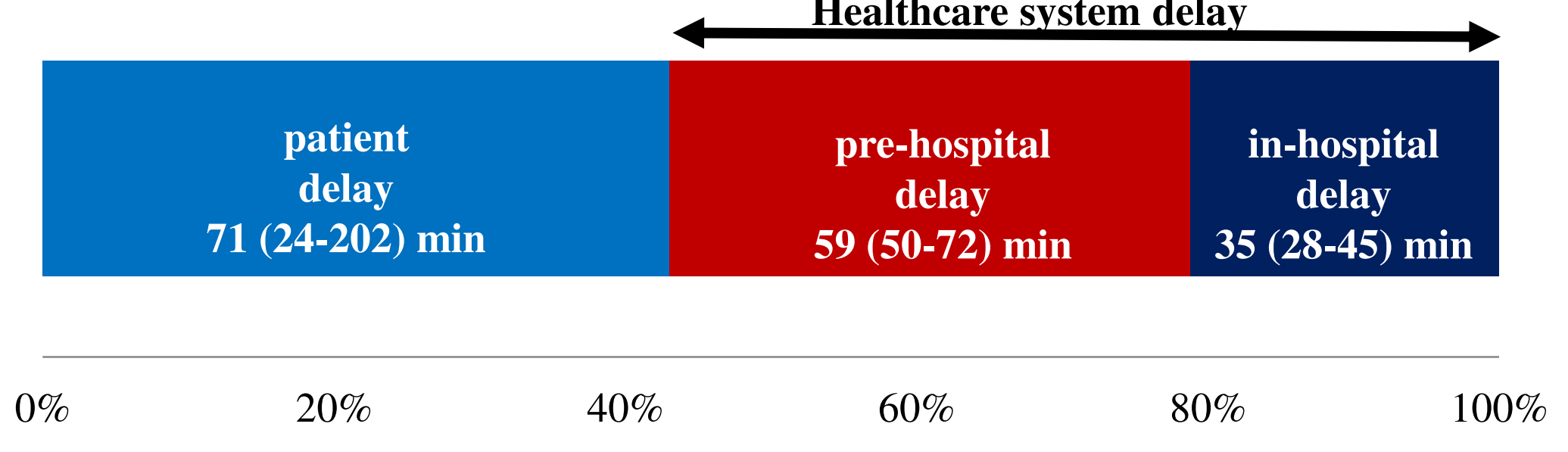

TABLE 2: Distribution of pre-hospital delay

\begin{tabular}{|c|c|c|c|}
\hline & \multicolumn{3}{|c|}{ pre-hospital phase } \\
\hline & $\begin{array}{l}\text { EMS call to FMC } \\
\qquad(\mathrm{n}=573)\end{array}$ & $\begin{array}{r}\text { on scene } \\
(\mathrm{n}=447)\end{array}$ & $\begin{array}{c}\text { transport } \\
(\mathrm{n}=447)\end{array}$ \\
\hline me (IQR) & $10(7-13) \min$ & $24(19-30) \min$ & $22(17-28) \min$ \\
\hline $\min$ & $1 \mathrm{~min}$ & $1 \mathrm{~min}$ & $5 \mathrm{~min}$ \\
\hline $\max$ & $52 \min$ & $71 \mathrm{~min}$ & $89 \min$ \\
\hline
\end{tabular}

TABLE 3: Relationship between the occurrence of in-hospital death and the time from FMC to patient hospital admission - one and multidimensional model

\begin{tabular}{lllllll} 
& $\mathrm{OR}^{\mathrm{A}}$ & $95 \% \mathrm{CI}$ & & $\mathrm{OR}^{\mathrm{B}}$ & $95 \% \mathrm{CI}$ & \\
\hline $\begin{array}{l}\text { time from FMC to patient } \\
\text { admission }\end{array}$ & 1,022 & 1,002 & 1,04 & 1,005 & 0,976 & 1,035 \\
\hline
\end{tabular}

OR - Odds Ratio

A - one-dimensional model

B - multivariable model including drugs + age + sex + distance + diabetes + hypertension + hypercholesterolemia + renal failure + shock 